\title{
Genetic responses against nitric oxide toxicity
}

\section{B. Demple}

\section{Correspondence}

B. Demple

Department of Cancer Cell Biology

and Division of Biological Sciences

Graduate Program

Harvard School of Public Health

Boston, MA 02115

USA

Fax: + 1-617-432-2590/432-0377

E-mail: bdemple@ hsph.harvard.edu

Presented at the Meeting

"NO Brazil, Basic and Clinical

Aspects of Nitric $O$ xide",

Foz do Iguaçu, PR, Brazil

March 10-13, 1999.

Research supported by the National Institutes of $\mathrm{H}$ ealth, USA.

Received May 28, 1999

Accepted July 12, 1999
Department of Cancer Cell Biology and

Division of Biological Sciences Graduate Program,

$\mathrm{H}$ arvard School of Public Health, Boston, MA, USA

\section{Abstract}

The threat of free radical damage is opposed by coordinated responses that modulate expression of sets of gene products. In mammalian cells, 12 proteins are induced by exposure to nitric oxide (NO) levels that are sub-toxic but exceed the level needed to activate guanylate cyclase. Heme oxygenase 1 (HO-1) synthesis increases substantially, due to a 30 - to 70 -fold increase in the level of HO-1 mRNA. HO-1 induction is cGMP-independent and occurs mainly through increased mRNA stability, which therefore indicates a new NO-signaling pathway. $\mathrm{HO}-1$ induction contributes to dramatically increased NO resistance and, together with the other inducible functions, constitutes an adaptive resistance pathway that also defends against oxidants such as $\mathrm{H}_{2} \mathrm{O}_{2}$. In E. coli, an oxidative stress response, the soxRS regulon, is activated by direct exposure of $E$. coli to NO, or by NO generated in murine macrophages after phagocytosis of the bacteria. This response is governed by the SoxR protein, a homodimeric transcription factor (17-kDa subunits) containing [2Fe-2S] clusters essential for its activity. SoxR responds to superoxide stress through one-electron oxidation of the iron-sulfur centers, but such oxidation is not observed in reactions of NO with SoxR. Instead, NO nitrosylates the iron-sulfur centers of SoxR both in vitro and in intact cells, which yields a form of the protein with maximal transcriptional activity. Although nitrosylated SoxR is very stable in purified form, the spectroscopic signals for the nitrosylated iron-sulfur centers disappear rapidly in vivo, indicating an active process to reverse or eliminate them.

\section{Introduction}

Nitric oxide (NO) occurs widely in biology and has diverse effects. NO is generated enzymatically by a class of $\mathrm{P}_{450}$-related enzymes called NO synthases (NOS), which use $\mathrm{O}_{2}$ and NADPH to produce NO by oxidation of L-arginine $(1,2)$. Immune cells employ NO as a cytotoxic weapon to destroy pathogens and tumor cells (3). Activation of

\section{Key words}

- Oxidative stress

- SoxR protein

- Heme oxygenase 1

- RNA stability

- Transcriptional

regulation macrophages by interferon $\gamma$ or bacterial lipopolysaccharide leads to the induced synthesis of an NOS that produces high (micromolar) levels of NO continuously for many hours (1). The NO produced by murine macrophages is important for killing both microbial pathogens and tumor cells $(3,4)$. Some bacterial pathogens have evolved the ability to sense and respond to their exposure to macrophage-generated NO $(5,6)$; the bacte- 
rial defense mechanisms involved in this response provide important clues to the cytotoxic reactions in target cells and suggest that adaptive responses to NO might exist in other organisms.

NO damage in phagocytosed cells includes protein modification, such as the formation of 3-nitrotyrosine adducts (7), the inactivating nitrosylation of iron-sulfur centers in enzymes such as aconitase (8) or the inactivation of ribonucleotide reductase (9). Cytotoxic DNA damage is also produced in NO-exposed cells (10).

$\mathrm{NO}$ at much lower (nanomolar) levels is employed for intercellular signaling in mammalian tissues (Figure 1). In vascular endothelial cells, a calcium-sensitive NOS is activated when neuronal electrochemical signals activate the endothelium (11). The resulting NO then diffuses to neighboring smooth muscle cells, binds the heme group of soluble (heme-containing) guanylate cyclase, and cGMP production leads to muscle relaxation (12). Recent observations (13) add to this model by suggesting that NO carried as a nitrosothiol adduct on the conserved surface cysteine residue of hemoglobin can be released within oxygen-deprived tissues, thus increasing blood flow.

In addition, NO seems to operate as a signal molecule between neuronal cells. In several systems, arginine analogs that block NOS activity also prevent cell-cell communication, such as that underlying long-term potentiation (14). Initially this effect was

Figure 1 - Nitric oxide (NO) levels and biological effects. NOS, NO synthases.

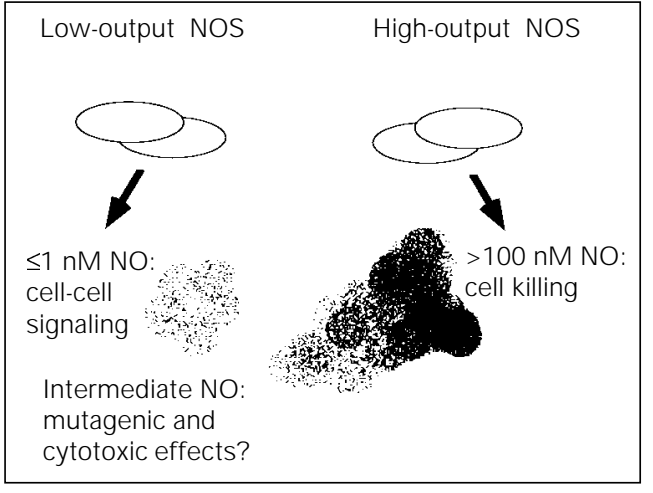

assumed to depend on the specific neuronal form of NOS, but mice in which the gene encoding this enzyme was mutated retained apparently normal long-term potentiation (15). Instead, both the neuronal and endothelial isoforms of NOS act in long-term potentiation (16), an observation that preserves the role of $\mathrm{NO}$ in the process.

Many other cell types are now known to generate NO, particularly from an NOS that is strongly induced in response to cytokines. Induction of this same NOS isoform has been extended to hepatocytes (17), fibroblasts (18), and glial cells $(19,20)$. A recent report suggested that AIDS-related dementia is caused by cytokine-induced expression of the inducible NOS in the central nervous system (21), which illustrates its potential for cellular damage as a by-product of inflammatory NO production. Exposure to $\mathrm{NO}$ through both the inducible NOS and the isoforms involved in intercellular signaling may constitute a common toxic threat in mammalian tissues.

In view of the toxicity of $\mathrm{NO}$ outlined above, frequent exposure might have provoked the evolution of defenses to cope with it. Some of the activities marshaled against reactive derivatives of oxygen probably contribute to normal cellular resistance to NO. For example, our own work has shown that superoxide dismutase (SOD) can function as a defense against $\mathrm{NO}$ (5), probably by limiting the formation of peroxynitrite $\left(\mathrm{ONOO}^{-}\right)$ from the reaction of superoxide $\left(\mathrm{O}_{2}^{-}\right)$with NO. Peroxynitrite is a highly reactive species capable of damaging all biological macromolecules (22). Glutathione in CHO cells and human lymphoblastoid cells (23), and in rat neuronal cells (24) provides protection from the toxicity of chemically or biologically generated NO. DNA repair enzymes that correct other forms of oxidative damage may also act on NO-dependent lesions $(5,25)$. In addition to the constant expression of defense activities, it also seemed possible that cells might modulate their resistance to 
NO by transient changes in gene expression, as they do in the face of other types of cytotoxic and mutagenic threats.

Free radicals and oxidative damage to cellular components, especially DNA and the resulting oxidative mutagenesis, have been argued frequently to be a key underlying cause of cancer and other age-related diseases (see review by Ames and colleagues (26)). While much of the evidence supporting this view has traditionally been circumstantial in nature, recent genetic experiments support the critical role of antioxidant defenses in animal viability (e.g., the early death of mice lacking mitochondrial SOD; 27). Collectively, the results of studies of this type support the hypothesis that there is considerable risk of oxidative damage due to normal aerobic metabolism. The recognition that $\mathrm{NO}$ is also a normal product in mammalian cells has suggested that this molecule might also contribute to age-related diseases such as cancer $(28,29)$. The roles of NO in carcinogenesis are likely to be as variable as the biological effects of this agent in cell-cell signaling and cytotoxicity. For example, it has been proposed that the angiogenic and cytotoxic properties of NO may combine to select tumor cells with p53 mutations (30). Because the mutagenic and cytotoxic potential of NO has important implications for carcinogenesis $(31,32)$, it is critical to understand in molecular terms the cellular defenses that operate against NO-mediated damage. Conversely, resistance mechanisms might operate in tumor cells to counter the attack of immune cells that employ $\mathrm{NO}$ as part of their cell-killing weaponry (3).

From the foregoing, one can propose that the ability of cells to modulate their sensitivity to $\mathrm{NO}$ is an important feature of the etiology of age-related diseases such as cancer. There is now evidence that mammalian cells can activate an adaptive response to $\mathrm{NO}$, in which subtoxic levels of this free radical cause gene induction that allows the survival of otherwise toxic concentrations of
NO $(33,34)$. We have shown specific defense gene induction by NO in human fibroblasts and HeLa cells (35), and we have demonstrated that this induction increases the NO resistance of rodent motor neurons (36).

The E. coli soxRS system $(37,38)$ works in two transcriptional stages (39): "resting" SoxR protein contains [2Fe-2S] centers that are in the reduced state (formal charge +2 ) in the absence of oxidative stress, but which become oxidized (formal charge +3 ) upon cellular exposure to superoxide-generating agents such as paraquat (PQ). Activated SoxR triggers transcription of the soxS gene up to 100 -fold $(40,41)$, and the resulting synthesis of SoxS protein (42) stimulates 15 other genes encoding key defense and metabolism proteins (Figure 1): Mn-containing SOD $(\operatorname{sod} A)$, DNA repair endonuclease IV (nfo), glucose-6-phosphate dehydrogenase $(z w f)$, aconitase (acnA), stable fumarase ( $f u m C$ ), ferredoxin:NADPH oxido-reductase $(f p r)$, toxin and antibiotic efflux pumps (acrAB), an antisense RNA for the ompF porin mRNA (micF), etc. (43). This coordinate induction gives increased cellular resistance to oxidative agents such as PQ $(37,38)$ (Figure 2).

Unexpectedly, soxRS activation also increases the resistance to a wide range of antibiotics (37), dependent on both micF, to affect OmpF expression (44), and the acr $A B$ efflux pump (45). This antibiotic resistance mechanism is also activated by the $\operatorname{mar} R A B$ locus, which employs a close homolog of SoxS, MarA protein ( $42 \%$ identical to SoxS; 46), to stimulate expression of many of the same genes. A third protein, called Rob, has an N-terminal domain very similar to SoxS and MarA and can also activate multiple

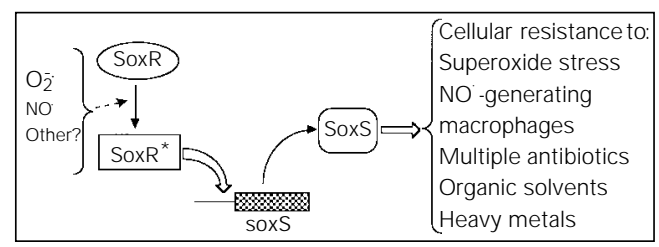

Figure 2 - Two-stage gene activation in the soxRS regulon. Synthesis of SoxS protein triggers resistance genes. SoxR*, the activated form. NO, Nitric oxide. Reprinted with permission from Ref. 39. 
antibiotic resistance (47). All three proteins (SoxS, MarA, and Rob) activate at least some oxidative stress genes, such as sodA $(47,48)$, which indicates a close relationship between defenses against oxidative stress and other environmental agents.

The soxRS system is activated by NO, even in the absence of oxygen (5). Induction of soxRS by this immune system weapon provides $E$. coli with some resistance to NOgenerating macrophages $(5,6)$. The mechanism by which NO activates SoxR has been of particular interest, but until recently has resisted solution. Our recent work now shows that the SoxR [2Fe-2S] centers are directly modified by NO, but also suggests that additional pathways exist that process NO-modified iron-sulfur proteins. Similar mechanisms for dealing with $\mathrm{NO}$ damage probably exist in mammalian cells.

We have exploited the soxRS system as a model for redox signal transduction, resulting in a novel model of gene control dependent on the oxidation state of iron-sulfur centers (39). The physical processes underlying this signaling, and the detailed control of the SoxR oxidation state by cellular activities, still remain to be established. The versatile role of the SoxR [2Fe-2S] centers in signaling free radicals is likely to be replayed in other systems, not necessarily restricted to transcriptional regulators.

\section{An NO-inducible response in human cells}

\section{$\mathrm{NO}$-inducible proteins in human fibroblasts}

We set out to determine whether human cells have a global response to sub-toxic NO detectable as the induced synthesis of specific proteins. We wished initially to use untransformed cells, and so chose IMR-90 primary human embryonic lung fibroblasts. The pathways of NO-induced gene expression in fibroblasts are likely to be relevant to other cell types, because fibroblasts may be exposed acutely to macrophage-generated NO during wound healing or pathogen-induced inflammation. As noted in the Introduction, cytokine-inducible NOS is also found in fibroblasts, which may thus generate their own burden of NO exposure.

IMR-90 cells (human embryonic lung fibroblasts) were cultured just to confluence and exposed to varying doses of pure $\mathrm{NO}$ gas, applied at known rates through gaspermeable Silastic tubing. This exposure method (49) allows NO levels to be controlled precisely and avoids the by-products of NO-releasing compounds; the exposure is estimated by measuring nitrite with the Griess reagent.

After a 90-min exposure to $\mathrm{NO}$ at 280 $\mathrm{nM} / \mathrm{s}$ and subsequent protein labeling by ${ }^{35} \mathrm{~S}$-methionine, two-dimensional gel analysis revealed the reproducible induction of twelve proteins in NO-exposed cells compared to controls, and the repression of eight others (35). The levels of NO employed in these experiments are within the physiological range (Figure 1) for the amounts generated by the inducible NOS of macrophages and other cell types $(3,49,50)$. Indeed, the NO fluxes given here correspond to the total amount absorbed in the exposed culture, such that the actual NO steady-state concentration at the surface of attached cells is likely to be lower, owing to reaction of $\mathrm{NO}$ with dissolved oxygen in the culture medium (which generates nitrite and nitrate; control experiments show that these products do not mediate the observed protein induction by $\mathrm{NO}$ ).

Most of the induced proteins remain to be identified (Figure 3), but a prominent NO-inducible polypeptide in the two-dimensional gels had $M_{r} \sim 32,000$ (35). Since mammalian cells treated with other oxidative agents (e.g., hydrogen peroxide or sodium arsenite) induce a $32-\mathrm{kDa}$ protein, identified as heme oxygenase 1 (HO-1) (51), we tested directly whether NO treatment induces the HO-1 mRNA in human cells. 


\section{Dose-dependent induction of HO-1 mRNA}

Quantitative Northern blot analysis (35) revealed that the HO-1 transcript is indeed strongly induced in IMR-90 cells exposed to NO for 90 min at dose rates as low as $90 \mathrm{nM} /$ s; a similar dose-dependence was observed for HeLa cells. Up to 10-fold induction of HO-1 mRNA was seen for both cell types at dose rates $\sim 550 \mathrm{nM} / \mathrm{s}$, which is lower than the local NO production expected for a fully activated macrophage $(1,3)$. The NO levels employed for these treatments were not cytotoxic, as assessed by clonal assays or Trypan blue exclusion (Marquis JC and Demple B, unpublished data). The induction of the HO-1 transcript by sub-toxic NO levels may represent a component of a protective response. Indeed, HO-1 induction by NO-donating compounds has now been reported in rat hepatocytes (52), a glioblastoma cell line (53), vascular endothelial cells (54), and vascular smooth muscle cells (33). In addition, induction of HO-1 was reported for rat glial cells associated with induction of NOS activity (20).

The induction of HO-1 mRNA by NO in IMR-90 cells was optimized with respect to the time of exposure and the subsequent NOfree incubation. In these experiments, we used conditioned medium to avoid the HO-1 induction that occurs when fresh medium is used (51). Doses were controlled by varying the length of silicon tubing used for the exposure, the concentration of NO gas (balanced by argon) flowing through the silicon tubing, and the time of exposure. We determined the exposure conditions for optimal $\mathrm{HO}-1$ expression to be $280 \mathrm{nM} / \mathrm{s}$ for $60 \mathrm{~min}$, which gave induction up to 70 -fold over control (conditioned medium) levels. The kinetics of this induction were such that, after a 60-min pulse exposure to NO (followed by medium replacement and incubation), maximal induction was seen 3-5 $\mathrm{h}$ later (35). Western blotting demonstrated increased levels of $\mathrm{HO}-1$ protein for at least 10 $h$ after the exposure (35).

Maximal expression of HO-1 mRNA could be sustained for at least $8 \mathrm{~h}$ during continuous low-level exposure to NO. Since the NO dose rate was inversely proportional to the exposure time in these experiments (35), strong HO-1 expression could be seen even at a dose rate of $\sim 35 \mathrm{nM} / \mathrm{s}$. This level is biologically relevant, as noted above, and motor neurons respond to NO fluxes that are even 10-fold lower (see below). Prolonged exposures such as that shown here begin to approach the kind of chronic exposure expected for in vivo situations.

The lack of dramatic NO-mediated induction with the HO-1 reporter constructs (35) suggested either that key transcriptional elements are missing from these constructs, or that post-transcriptional changes lead to HO-1 mRNA induction. We tested the latter possibility by determining the stability of HO-1 mRNA in untreated and NO-treated cells. In control (untreated) IMR-90 cells, HO-1 mRNA had a half-life of $<2 \mathrm{~h}$, which was dramatically increased to $\sim 6 \mathrm{~h}$ immediately after the NO treatment (35). The decay rate of HO-1 mRNA was determined at various times after stopping NO exposure, which showed that the stability of the message returned to the pre-treatment level by $4 \mathrm{~h}$

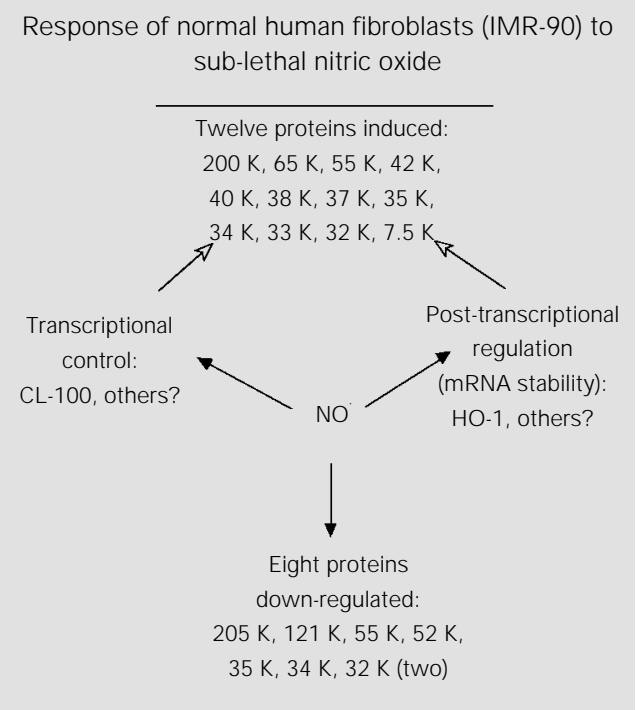

Figure 3 - Constellation of nitric oxide (NO)-inducible proteins in human IMR-90 fibroblasts. HO1, Heme oxygenase 1. Reprinted with permission from Ref. 64 
post-exposure (35). Essentially the same result was obtained with two different RNA polymerase II inhibitors (35). There was no evidence for an NO-induced change in the stability of the CL100/MKP-1 or SOD2 mRNA (data not shown). This result suggests that the activity of regulatory proteins that bind HO-1 mRNA is controlled in response to NO (Figure 3).

\section{An adaptive response of motor neurons to NO}

Since sub-toxic NO exposure led to induction of the protective enzyme HO-1 in

Figure 4 - Kinetics of adaptive nitric oxide (NO) resistance in NSC34 cells. The cells were pretreated for 60 min with $25 \mathrm{nM} / \mathrm{s}$ $\mathrm{NO}$ or argon gas (control; C). After incubation in NO-free medium for the indicated times, samples were taken for Northern blotting and quantification (panel A), or challenged for 60 min with $277 \mathrm{nM} / \mathrm{s}$ NO. After an additional 24-h incubation, viability (panel B) was measured. HO1 , Heme oxygenase 1 . Reprinted with permission from Ref. 36.
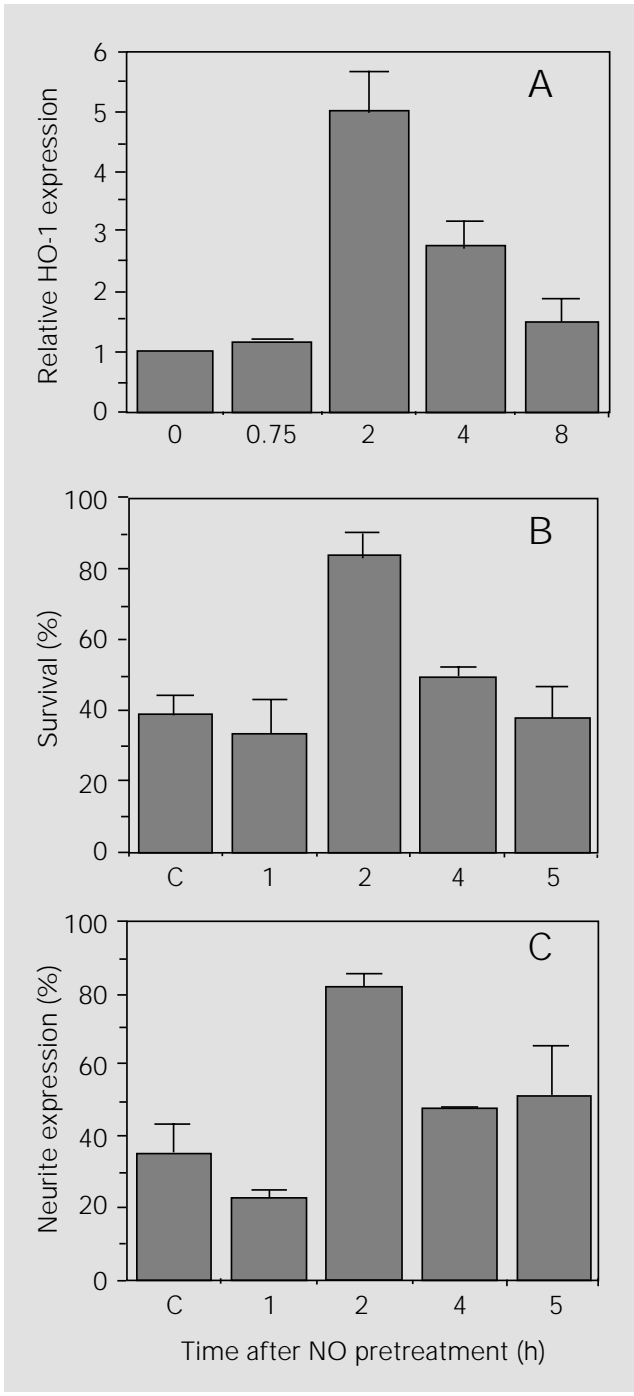

human fibroblasts and HeLa cells, we tested whether such a response also occurs in other cell types. We investigated this question initially for motor neurons as representative of long-lived cell types that may be at chronic risk of NO damage both from inflammation and from by-products of intercellular signaling processes involving NO. We initially tested the immortalized spinal cord neuronneuroblastoma cell line NSC34, developed by Cashman and colleagues (55). After plating under suitable growth conditions, this line displays all the essential morphological and biochemical characteristics of mature motor neurons $(56,57)$.

We first established the cytotoxicity of different NO flux rates for NSC34 cells (36). Under our culture and exposure conditions, a 60 -min exposure to $\mathrm{NO}$ at $35 \mathrm{nM} / \mathrm{s}$ did not cause detectable cell death or loss of neurites, a key indicator of neuronal integrity (55, 56). At NO fluxes of 83-277 nM/s, substantial cell death and neurite loss ensued within $24 \mathrm{~h}$.

As assessed by Northern blotting, HO-1 expression was induced rapidly and dramatically in NSC34 cells following subtoxic NO treatments. After 60-min exposures to 25$40 \mathrm{nM} / \mathrm{s} \mathrm{NO}$, followed by a 2-h expression period, HO-1 RNA was induced 5- to 6-fold (Figure 4). In contrast, exposure to cytotoxic levels of NO diminished or eliminated the induction. Varying the expression time after a 60-min exposure to $\mathrm{NO}$ at $25 \mathrm{nM} / \mathrm{s}$ showed that HO-1 mRNA induction was maximal $2 \mathrm{~h}$ after treatment, but had decreased nearly to control levels by $8 \mathrm{~h}$ (Figure 4 ). As found for human fibroblasts (35), the induction of HO-1 mRNA by NO was evidently independent of cGMP: the membrane-permeable analog 8-bromo-cGMP (12) failed to elicit HO-1 mRNA accumulation (36). The MnSOD (SOD2) transcript was not induced in NO-exposed NSC34 cells (Bishop A and Demple B, unpublished data).

Pretreatment of NSC34 cells for $60 \mathrm{~min}$ with a flux of $25 \mathrm{nM} / \mathrm{s} \mathrm{NO}$, followed by a 2 - 
$\mathrm{h}$ incubation to allow induced gene expression, conferred substantial resistance to a subsequent cytotoxic NO challenge $(277 \mathrm{nM} /$ $\mathrm{s}$ for $60 \mathrm{~min}$ ), as judged by microscopic examination for cell survival $24 \mathrm{~h}$ after the challenge (36) (Figure 4). The loss of neurite-bearing cells after the NO challenge was significantly less for the pretreated NSC34 cells than for those challenged directly with a high level of NO (36). After NO challenge of the non-pretreated cells, microscopic examination revealed the accumulation of considerable cellular debris accompanying degradation and rounding of the remaining adherent cells (36). Among these survivors, the axons of the few neurite-bearing cells were spiny and appeared to be undergoing Wallerian degeneration, a morphological characteristic of neuronal degeneration (58).

The time course of the NO-induced cytotoxic effects revealed significant protection by an inducing pretreatment as early as $2 \mathrm{~h}$ after the challenge (36). For the non-pretreated cells, the loss of Trypan blue exclusion at $2 \mathrm{~h}$ after the NO challenge was accompanied by cell rounding and shrinkage suggestive of apoptosis (Bishop A and Demple B, unpublished data). A quantitative analysis of neuronal morphology as an indicator of inducible NO resistance showed that essentially all the viable cells in the pretreated population expressed neurites $48 \mathrm{~h}$ after the NO challenge, compared to $\sim 35 \%$ for the NO-challenged control cells at $48 \mathrm{~h}$ (36). Thus, NSC34 cells can activate adaptive resistance to NO. As these experiments were underway (1996-present), adaptive resistance to NO-releasing compounds was reported for rat hepatocytes (59), vascular endothelium $(54,60)$, and vascular smooth muscle cells (33). Thus, adaptive NO resistance is a very widespread response displayed by many cell types and may constitute a fundamental defense mechanism of mammalian cells. It is likely that some key functions, such as HO-1, are employed in the adaptive resistance to NO of many cell types.
We have since demonstrated an even more robust adaptive resistance to NO in IMR-90 human fibroblasts (Teixeira $\mathrm{H}$ and Demple $\mathrm{B}$, unpublished data).

Adaptive NO resistance probably involves multiple defense pathways, in view of the complex chemistry and array of targets of NO noted above. We therefore tested whether sublethal NO increases resistance to other oxidants (36). Indeed, after challenge of NO-adapted NSC34 cells with hydrogen peroxide (a 60-min incubation with $100 \mu \mathrm{M}$ hydrogen peroxide) and subsequent incubation, a vital stain assay showed higher survival in the NO-pretreated cells (77\%) than in control cells (40\%). Thus, the adaptive resistance to $\mathrm{NO}$ also involves defense mechanisms that also counteract cytotoxic peroxide damage.

The kinetics of adaptive NO resistance in NSC34 cells paralleled the expression of the HO-1 transcript. When the cells were pretreated with a subtoxic NO level and allowed various expression times before a toxic $\mathrm{NO}$ challenge, induced resistance was not apparent after only $1 \mathrm{~h}$ of expression time following the pretreatment (Figure 4). The maximum resistance was observed at $2 \mathrm{~h}$, which then decayed over the next few hours. The cellular survival reached the control level by $5 \mathrm{~h}$ after the pretreatment (Figure 4), although at this time there was still some protective effect observed in terms of neurite expression (36). This kinetics is consistent with at least partial dependence of the induced NO resistance on induced HO-1 expression.

To test the role of HO- 1 in adaptive $\mathrm{NO}$ resistance more directly, NSC34 cells were exposed to subtoxic $\mathrm{NO}$ in the presence of heme analogs that are HO-1 inhibitors. Since these compounds also inhibit heme-containing guanylate cyclase (12), 8-bromo-cGMP was also added in some experiments in order to restore cGMP pathways. Sn-protoporphyrin did not exert NO-independent cytotoxicity in NSC34 cells (Bishop A and Demple B, 
unpublished data), but it did abolish the adaptive resistance when present during the NO challenge (36). When 8-bromo-cGMP was added together with the Sn-protoporphyrin inhibitor, adaptive resistance was only partially restored (mean survival $27 \pm 3 \%$ in 3 experiments (36)). Moreover, incubation of non-pretreated cells with 8-bromo-cGMP did not detectably elevate their resistance to $\mathrm{NO}$, and a more specific guanylate cyclase inhibitor $(1 \mathrm{H}-(1,2,4)$ oxadiazole $(4,3-\alpha)$ quinoxalin-1-one) did not diminish adaptive NO resistance (36). Thus, the role for cGMPdependent mechanisms appears at most to be secondary, and the induced expression of HO-1 may be necessary for this contribution to be detected.

\section{Activation of SoxR by nitric oxide}

The E. coli soxRS regulon (Figure 2) is activated by pure $\mathrm{NO}$ gas and contributes to bacterial resistance to NO-generating mouse macrophages (5). For a direct test of the role of macrophage-generated NO in SoxR activation, we developed high-sensitivity methods to monitor sox $S^{\prime}:$ :lacZ expression of phagocytosed bacteria directly within macrophages (6). This approach demonstrated an exact parallel between sox $S$ induction (which reports SoxR activation) and soxRSdependent resistance to NO. The use of an NO synthase inhibitor (NE-methyl-L-arginine) showed that SoxR activation depends on the activity of the macrophage NO-generating enzyme (6). Thus, a direct link was established between physiological NO levels and SoxR activation.

The mechanism of NO activation of SoxR was not established in the previous experiments. However, because soxRS activation by $\mathrm{NO}$ is more effective anaerobically than aerobically $(6,61), \mathrm{O}_{2}{ }^{-}$or other $\mathrm{O}_{2}$-dependent molecules are not involved. The results are instead consistent with the direct reaction of SoxR with NO. We have now discovered the basic mechanism by which NO activates SoxR. We exposed cells to NO "instantaneously" by adding aliquots of a saturated solution of the pure gas (made anaerobically in water), and we monitored soxS induction directly by Northern blotting. These experiments showed rapid but transient induction of soxS mRNA to a high level (Ding $\mathrm{H}$ and Demple B, unpublished results). Extending the NO exposure from $<10$ $\mathrm{s}$ to $30 \mathrm{~s}$ gave a longer-lived activation of soxS transcription, which peaked at $5 \mathrm{~min}$ and decayed over the next 15 min (Ding $\mathrm{H}$ and Demple B, unpublished results). These results are consistent with the generation by NO of a transiently activated form of SoxR.

Electron paramagnetic resonance (EPR) spectroscopy of intact, NO-treated E. coli revealed a new SoxR species with $g=2.03$ (Ding $\mathrm{H}$ and Demple B, unpublished results). This EPR signature was similar to those of dinitrosyl-iron-dithiol complexes, the predominant known product of $\mathrm{NO}$ with iron-sulfur centers in vivo $(8,62,63)$. For SoxR, these adducts were formed rapidly (within 2 min of NO exposure) under conditions where the induction of soxS was maximal. After NO exposure, the EPR signal returned rapidly to that of reduced, unmodified SoxR, in parallel to the down-regulation of soxS (Ding H and Demple B, unpublished results).

The $g=2.03$ EPR spectrum was reproduced in vitro with purified SoxR protein treated with NO (Ding H and Demple B, unpublished results); therefore, other cellular components are not required. The dinitrosyl-iron-dithiol complexes in SoxR were very stable in vitro, even after partial reduction with dithionite and re-oxidation. This stability contrasts with the rapid disappearance of nitrosylated SoxR in vivo and suggests that NO-modified SoxR is actively eliminated in intact cells.

Nitrosylation of iron-sulfur centers typically inactivates protein function. However, NO-treated SoxR, in which the iron-sulfur centers had been completely modified, was 
just as active in in vitro transcription as the oxidized form of Fe-SoxR (Ding $\mathrm{H}$ and Demple B, unpublished results). Thus, SoxR is the first example of a protein activated by nitrosylation of its iron-sulfur centers (Figure 5), and this mechanism provides a new mode of signal transduction involving NO. It seems likely that this form of signaling would be employed in mammalian cells.

\section{Acknowledgments}

The author is indebted to his many tal-

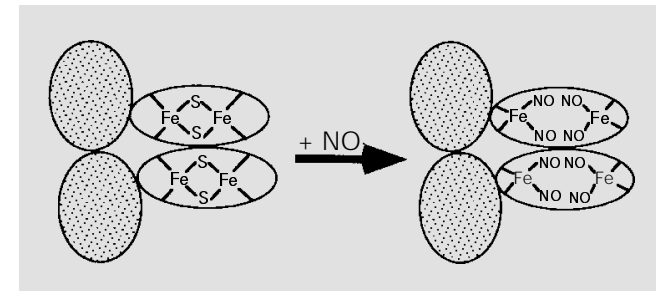

Figure 5 - Model for SoxR activation by nitric oxide (NO). Reaction with $\mathrm{NO}$ converts the [2Fe$2 \mathrm{~S}]$ centers to nitrosylated adducts. The protein is shown as a homodimer; the stippled regions correspond to the DNA-binding domains, distinct from the [2Fe2S] domains.

\section{References}

1. Marletta MA (1993). Nitric oxide synthase: function and mechanism. Advances in Experimental Medicine and Biology, 338: 281-284.

2. Crane BR, Arvai AS, Ghosh DK, Wu C, Getzoff ED, Stuehr DJ \& Tainer J A (1998). Structure of nitric oxide synthase oxygenase dimer with pterin and substrate. Science, 279: 2121-2126.

3. MacM icking J , Xie QW \& Nathan C (1997). Nitric oxide and macrophage function. Annual Review of Immunology, 15: 323-350.

4. Hibbs J BJ , Taintor RB, Vavrin Z \& Rachlin EM (1988). Nitric oxide: A cytotoxic activated macrophage effector molecule. Biochemical and Biophysical Research Communications, 157: 87-94.

5. Nunoshiba T, deRojas-Walker T, Wishnok J S, Tannenbaum SR \& Demple B (1993). Activation by nitric oxide of an oxidativestress response that defends Escherichia coli against activated macrophages. Proceedings of the National Academy of Sciences, USA, 90: 9993-9997.

6. Nunoshiba $T$, deRojas-Walker $T$, Tannenbaum SR \& Demple B (1995). Roles of nitric oxide in inducible resistance of Escherichia coli to activated murine macrophages. Infection and Immunity, 63: 794-798.

7. Kooy NW, Lewis SJ, Royall J A, Ye YZ, Kelly DR \& Beckman J S (1997). Extensive tyrosine nitration in human myocardial inflammation: evidence for the presence of peroxynitrite. Critical Care Medicine, 25: 812-819.

8. Drapier J -C (1997). Interplay between NO and (Fe-S) clusters: Relevance to biological systems. Methods, 11: 319-329.

9. Kwon NS, Stuehr DJ \& Nathan CF (1991).
Inhibition of tumor cell ribonucleotide reductase by macrophage-derived nitric oxide. J ournal of Experimental Medicine, 174: 761-767.

10. Tamir S, Burney $S \&$ Tannenbaum SR (1996). DNA damage by nitric oxide. Chemical Research in Toxicology, 9: 821827.

11. Schmidt HHHW \& Walter U (1994). NO at work. Cell, 78: 919-925.

12. Hobbs AJ \& Ignarro LJ (1996). Nitric oxide-cyclic GMP signal transduction system. Methods in Enzymology, 269: 134148.

13. Stamler J S, Jia L, Eu J P, Mcmahon TJ , Demchenko IT, Bonaventura J , Gemert K \& Piantadosi CA (1997). Blood flow regulation by S-nitrosohemoglobin in the physiological oxygen gradient. Science, 276: 2034-2037.

14. Brenman JE \& Bredt DS (1996). Nitric oxide signaling in the nervous system. Methods in Enzymology, 269: 119-129.

15. O'Dell TJ, Huang PL, Dawson TM, Dinerman J L, Snyder SH, Kandel ER \& Fishman MC (1994). Endothelial NOS and the blockade of LTP by NOS inhibitors in mice lacking neuronal NOS. Science, 265 : 542-546.

16. Son $\mathrm{H}$, Hawkins RD, Martin $\mathrm{K}$, Kiebler $\mathrm{M}$, Huang PL, Fishman MC \& Kandel ER (1996). Long-term potentiation is reduced in mice that are doubly mutant in endothelial and neuronal nitric oxide synthase. Cell, 87: 1015-1023.

17. Geller DA, Nussler AK, Di Silvio $M$, Lowenstein CJ, Shapiro RA, Wang SC, Simmons RL \& Billia TR (1993). Cytokines, endotoxin, and glucocorticoids regulate the expression of inducible nitric oxide synthase in hepatocytes. Proceedings of the National Academy of Sciences, USA, 90: 522-526.

18. Gilbert RS \& Herschman HR (1993). "Macrophage" nitric oxide synthase is a glucocorticoid-inhibitable primary response gene in 3 T3 cells. J ournal of Cellular Physiology, 157: 128-132.

19. Kawase $M$, Kinouchi $\mathrm{H}$, Kato I, Akabane $A$ Kondo T, Arai S, Fujimura M, Okamoto $\mathrm{H}$ \& Yoshimoto T (1996). Inducible nitric oxide synthase following hypoxia in rat cultured glial cells. Brain Research, 738: 319322.

20. Kitamura $Y$, Furukawa $M$, Matsuoka $Y$ Tooyama I, Kimura $H$, Nomura $Y \&$ Taniguchi T (1998). In vitro and in vivo induction of heme oxygenase-1 in rat glial cells - Possible involvement of nitric oxide production from inducible nitric oxide synthase. Glia, 22: 138-148.

21. Adamson DC, Wildemann B, Sasaki M, Glass J D, McArthur J C, Christov VI, Dawson TM \& Dawson VL (1996). Immunologic NO synthase: elevation in severe AIDS dementia and induction by HIV-1 gp41. Science, 274: 1917-1921.

22. Beckman J S, Chen J, Ischiropoulos $\mathrm{H} \&$ Crow JP (1994). Oxidative chemistry of peroxynitrite. Methods in Enzymology, 233: 229-240.

23. Luperchio S, Tamir $\mathrm{S} \&$ Tannenbaum SR (1996). NO-induced oxidative stress and glutathione metabolism in rodent and human cells. Free Radical Biology and Medicine, 21: 513-519.

24. Bolaños JP, Heales $S J R$, Peuchen $S$, Barker J E, Land J M \& Clark J B (1996). Nitric oxide-mediated mitochondrial damage - a potential neuroprotective role for 
glutathione. Free Radical Biology and Medicine, 21: 995-1001.

25. Demple B \& Harrison L (1994). Repair of oxidative damage to DNA: enzymology and biology. Annual Review of Biochemistry, 63: 915-948.

26. Ames BN, Shigenaga MK \& Hagen TM (1993). Oxidants, antioxidants and the degenerative diseases of aging. Proceedings of the National Academy of Sciences, USA, 90: 7915-7922.

27. Melov S, Schneider J A, Day BJ , Hinerfeld D, Coskun P, Mirra SS, Crapo JD \& Wallace DC (1998). A novel neurological phenotype in mice lacking mitochondrial manganese superoxide dismutase. $\mathrm{Na}$ ture Genetics, 18: 159-163.

28. Esumi H \& Tannenbaum SR (1994). U.S.J apan Cooperative Cancer Research Program: seminar on nitric oxide synthase and carcinogenesis. Cancer Research, 54: 297-301.

29. Ohshima H \& Bartsch H (1994). Chronic infections and inflammatory processes as cancer risk factors - Possible role of nitric oxide in carcinogenesis. Mutation Research, 305: 253-264.

30. Ambs S, Hussain SP \& Harris CC (1997). Interactive effects of nitric oxide and the p53 tumor suppressor gene in carcinogenesis and tumor progression (Review). FASEB J ournal, 11: 443-448.

31. Tamir S \& Tannenbaum SR (1996). The role of nitric oxide (NO) in the carcinogenic process. Biochimica et Biophysica Acta, 1288: F31-F36.

32. Wink DA, Vodovotz $Y$, Laval J, Laval F, Dewhirst MW \& Mitchell J B (1998). The multifaceted roles of nitric oxide in cancer. Carcinogenesis, 19: 711-721.

33. Hartsfield CL, Alam J , CookJ L \& Choi AM (1997). Regulation of heme oxygenase-1 gene expression in vascular smooth muscle cells by nitric oxide. American J ournal of Physiology, 273: L980-L988.

34. Takahashi K, Hara E, Ogawa K, Kimura D, Fujita H \& Shibahara S (1997). Possible implications of the inductions of human heme oxygenase-1 by nitric oxide donors. J ournal of Biochemistry, 121: 1162-1168.

35. Marquis J C \& Demple B (1998). Complex genetic response of human cells to sublethal levels of pure nitric oxide. Cancer Research, 58: 3435-3440.

36. Bishop A, Marquis J C, Cashman NR \& Demple B (1999). Adaptive resistance to nitric oxide in motor neurons. Free Radical Biology and Medicine, 26: 978-986.

37. Greenberg J T, Monach P, Chou JH, J osephy PD \& Demple B (1990). Positive control of a global antioxidant defense regulon activated by superoxide-generating agents in Escherichia coli. Proceedings of the National Academy of Sciences, USA, 87: 6181-6185.

38. Tsaneva IR \& Weiss B (1990). soxR, a locus governing a superoxide response regulon in Escherichia coli $\mathrm{K}-12$. J ournal of Bacteriology, 172: 4197-4205.

39. Hidalgo E, Ding H \& Demple B (1997). Redox signal transduction via iron-sulfur clusters in the soxR transcription factor. Trends in Biochemical Sciences, 22: 207210.

40. Hidalgo E \& Demple B (1994). An ironsulfur center essential for transcriptional activation by the redox-sensing SoxR protein. EMBO J ournal, 13: 138-146.

41. Gaudu P \& Weiss B (1996). SoxR, a (2Fe2S) transcription factor, is active only in its oxidized form. Proceedings of the National Academy of Sciences, USA, 93: 10094-10098.

42. Li Z \& Demple B (1994). SoxS, an activator of superoxide stress genes in E. coli. Purification and interaction with DNA. J ournal of Biological Chemistry, 269: 18371-18377.

43. Hidalgo E \& Demple B (1996). Adaptive responses to oxidative stress: the soxRs and oxyR regulons. In: Lin ECC \& Lynch AS (Editors), Regulation of Gene Expression in Escherichia coli. R.G. Landes, Austin, TX, 435-452.

44. Chou JH, Greenberg J T \& Demple B (1993). Posttranscriptional repression of E. coli OmpF protein in response to redox stress: positive control of the micF antisense RNA by the soxRS locus. J oumal of Bacteriology, 175: 1026-1031.

45. Ma D, Alberti M, Lynch C, Nikaido $H \&$ Hearst J E (1996). The local repressor AcrR plays a modulating role in the regulation of acrAB genes of Escherichia coli by global stress signals. Molecular Microbiology, 19: 101-112.

46. Ariza RR, Cohen SP, Bachhawat N, Levy SB \& Demple B (1994). Repressor mutations in the marRAB operon that activate oxidative stress genes and multiple antibiotic resistance in $\mathrm{E}$. coli. J ournal of Bacteriology, 176: 143-148.

47. Ariza RR, Li Z, Ringstad N \& Demple B (1995). Activation of multiple antibiotic resistance and binding of stress-inducible promoters by Escherichia coli Rob protein. J ournal of Bacteriology, 177: 16551661.

48. Greenberg JT, Chou J H, Monach PA \& Demple B (1991). Activation of oxidative stress genes by mutations at the soxQ/ cfxB/marA locus of Escherichia coli. J our- nal of Bacteriology, 173: 4433-4439.

49. Tamir S, Lewis RS, de Rojas Walker T, Deen WM, Wishnok J S \& Tannenbaum SR (1993). The influence of delivery rate on the chemistry and biological effects of nitric oxide. Chemical Research in Toxicology, 6: 895-899.

50. Tamir S, deRojas-Walker T, Gal A, Weller AH, Li X, Fox JG, Wogan GN \& Tannenbaum SR (1995). Nitric oxide production in relation to spontaneous B-cell lymphoma and myositis in SJ L mice. Cancer Research, 55: 4391-4397.

51. Tyrrell RM (1997). Approaches to define pathways of redox regulation of a eukaryotic gene: the heme oxygenase 1 example. Methods, 11: 313-318.

52. Kim Y-M, Bergonia HA, Müller C, Pitt BR, Watkins WD \& Lancaster J RJ (1995). Loss and degradation of enzyme-bound heme induced by cellular nitric oxide synthesis. J ournal of Biological Chemistry, 270: 5710-5713.

53. Takahashi K, Hara E, Suzuki H, Sasano H \& Shibahara S (1996). Expression of heme oxygenase isozyme mRNAs in the human brain and induction of heme oxygenase-1 by nitric oxide donors. J ournal of Neurochemistry, 67: 482-489.

54. Motterlini $R$, Foresti $R$, Intaglietta $M$ \& Winslow RM (1996). NO-mediated activation of heme oxygenase: endogenous cytoprotection against oxidative stress to endothelium. American J ournal of Physiology, 270: H107-H114.

55. Cashman NR, Durham HD, Blusztajn J K, Oda K, Tabira T, Shaw IT, Dahrouge S \& Antel J P (1992). Neuroblastoma $x$ spinal cord (NSC) hybrid cell lines resemble developing motor neurons. Developmental Dynamics, 194: 209-221.

56. Durham HD, Dahrouge $S \&$ Cashman NR (1993). Evaluation of the spinal cord neuron X neuroblastoma hybrid cell line NSC34 as a model for neurotoxicity testing. Neurotoxicology, 14: 387-395.

57. Matsumoto A, Yoshino $\mathrm{H}$, Yuki $\mathrm{N}$, Hara $Y$ Cashman NR, Handa $S \&$ Miyatake $T$ (1995). Ganglioside characterization of a cell line displaying motor neuron-like phenotype: GM2 as a possible major ganglioside in motor neurons. J ournal of the Neurological Sciences, 131: 111-118.

58. Escourolle R \& Poirier J (Editors) (1978). Manual of Basic Neuropathology. 2nd edn. W.B. Saunders, Philadelphia, 1-17.

59. Kim Y-M, Bergonia $H \& \&$ Lancaster J RJ (1995). Nitrogen oxide-induced autoprotection in isolated rat hepatocytes. FEBS Letters, 374: 228-232.

60. Polte T, Oberle S \& Schroder H (1997) 
The nitric oxide donor Sin-1 protects endothelial cells from tumor necrosis factoralpha mediated cytotoxicity - Possible role for cyclic GMP and heme oxygenase. J ournal of Molecular and Cellular Cardiology, 29: 3305-3310.

61. Nunoshiba T \& Demple B (1993). Potent intracellular oxidative stress exerted by the carcinogen 4-nitroquinoline-N-oxide.
Cancer Research, 53: 3250-3252.

62. Pellat C, Henry Y \& Drapier J C (1990). IFN-gamma-activated macrophages: detection by electron paramagnetic resonance of complexes between L-argininederived nitric oxide and non-heme iron proteins. Biochemical and Biophysical Research Communications, 166: 119-125.

63. Kennedy MC, Antholine WE \& Beinert H
(1997). An EPR investigation of the products of the reaction of cytosolic and mitochondrial aconitases with nitric oxide. J ournal of Biological Chemistry, 272: 20340-20347.

64. Demple B (1999). Radical ideas: Genetic responses to oxidative stress. Clinical and Experimental Pharmacology and Physiology, 26: 64-68. 